\title{
Editoriali
}

\section{Reducing the stigma of schizophrenia: understanding the process and options for interventions}

\author{
MATTHIAS C. ANGERMEYER and BEATE SCHULZE
}

In 1996, the World Psychiatric Association initiated a programme to reduce stigma and discrimination because of schizophrenia (Sartorius, 1998). Starting in Alberta (Canada), it was later joined by Spain and Austria. In the meantime, 11 countries from around the globe (including Italy) are involved in the international effort. Based on the respective local particularities of the countries participating, a multitude of interventions have been carried out or initiated in the context of the WPA-programme. The spectrum of activities extends from media campaigns through legal regulations to the empowerment of patients and their relatives.

In the following, it will be attempted to develop a-systematology of the various approaches aiming at reducing the stigma of schizophrenia. This is to facilitate orientation among the variety of strategies chosen. As a theoretical framework, the argument will draw on the conception of the stigma process developed by Link et al. (1997) (see also Link \& Phelan, in press). The process begins with a situation where a difference in another person is identified and subsequently labelled. It continues by linking the person thus labelled to negative stereotypes that prevail in society about the group of persons in question. Consequently, the person thus labelled is separated from others to become part of a distinct category from which people dissociate themselves. The stigma process culminates in that the person is exposed to various forms of discrimination, resulting in the respective negative social consequences.

Indirizzo per la corrispondenza: Professor M.C. Angermeyer, Department of Psychiatry, University of Leipzig, Johannisallee 20, 04317 Leipzig (Germany).

Fax: +49-341-9724539

E-mail: krausem@medizin.uni-leipzig.de

\section{NOTICING AND LABELLING DIFFERENCES}

At the outset of the stigma process, a distinguishing characteristic is noticed in someone and subsequently labelled. What, then, are the features through which people with schizophrenia can be differentiated from others? The first thing to mention are the acute psychotic symptoms through which those suffering from schizophrenia attract the attention of their social environment. While less apparent at first glance, the negative symptoms of the disorder and illness-related impairments are an additional distinguishing element. In addition, the undesired effects of psychotropic drug treatment are of importance in this regard. In particular, it is the extrapyramidal-motor side effects of the conventional neuroleptics through which the illness becomes visible for the patients' environment. From "discreditable" persons (Goffman, 1963) who can themselves decide whether to reveal their mental illness or not, they turn into "discredited" ones whose mental illness status is apparent through the parkinsoid resulting from their medication. However, it is not only these visible differences that matter. The fact that the diagnosis of schizophrenia becomes known to others alone is sufficient to get the stigma process going - regardless of whether the person in question presently displays symptoms of the illness or not. Even the mere fact that someone is receiving (or has received) psychiatric treatment is enough to be distinguished as different.

The visibility of the distinguishing feature plays an important part in deciding whether the stigma process is set off and which consequences ensue from it (Crocker et al., 1998). The more effective psychiatric treatment in the reduction of symptoms and illness-related impairments, the lower the risk of stigmatisation should be. Further, with a lower degree and frequency of visible medication side effects, those suffering from the illness 
should be increasingly protected from being stigmatised. Surely the introduction of the atypical neuroleptics represents a progress in this regard as they more rarely lead to extrapyramidal-motor side effects.

Where the stigmatising effect of the psychiatric diagnosis and the fact of being a psychiatric patient is concerned, two opposing strategies can be distinguished: medicalisation and normalisation. Proponents of medicalisation expect to achieve a de-stigmatising effect by integrating psychiatry as much as possible into medicine. They support the application of the medical disease concept to psychiatric disorders and encourage conceiving of mental illness in the same way as of physical illness. They propose a clear delineation between normality and mental illness which, in their eyes, represent two distinct categories. Psychiatry is understood as a specialist discipline within medicine. There is an emphasis on psychiatry's grounding in neuroscience. With regard to both its location and organisation, efforts are made to integrate psychiatry into medicine.

The strategy of "normalisers" pursues exactly the opposite objective: they distance themselves from medicine. Those favouring this approach avoid calling mental health problems an illness and prefer speaking of a "crisis". In their opinion, there is a continuum between normality and mental disorder. Its proponents strongly oppose the use of psychiatric diagnoses. This is particularly true for schizophrenia because of the stigma attached to this diagnosis. Labelling as a psychiatric "patient" is strictly avoided. Rather, those with mental health problems are called "clients", "users", "psychiatric consumers" (or even "psychiatric survivors"). Where location and organisation are concerned, there is a strong tendency to keep one's distance from the institutions of psychiatry.

The medicalisation approach is well received mainly by professional helpers in the medical field, and besides by many relatives. People with mental illness organised in advocacy groups, but also representatives of paramedical professional groups, on the other hand, show a stronger tendency to endorse the normalisation approach. The question as to which of the two strategies is more successful in avoiding the stigmatisation of people with schizophrenia, however, remains open. To date, only few studies exist that have dealt with this topic. Beyond, the evidence provided by them is rather contradictory. The medicalisation strategy, for example, appears to be preferable according to the results of Socall \& Holtgraves (1992) and Mechanic et al. (1994), while the findings of Farina et al. (1978), Fisher \& Farina (1979) and Rothaus et al. (1963) point in the opposite direction.

\section{ASSOCIATING HUMAN DIFFERENCES WITH NEGATIVE STEREOTYPES}

In the next step of the stigma process, the negative views about schizophrenia dominant in society are connected with a person identified as suffering from this ilIness. According to Hayward \& Bright (1997), the stereotype of the mentally ill is shaped by following four aspects: the view that people with mental illness are dangerous; that they are to blame for their illness; that the illness will take a chronic course, is difficult to treat and has a negative prognosis; and finally, that those with mental illness offend against the norms of social behaviour and are unpredictable. Where people with schizophrenia are concerned, their public image is dominated by the idea of unpredictability and dangerousness (Pescosolido et al., 1999; Crisp et al., 2000). The general public's desire to maintain social distance towards the mentally ill in general, and towards people with schizophrenia in particular, appears to be most strongly affected by the view that people with mental illness are violent. Causal attributions and ideas about the prognosis appear less important in shaping public attitudes. This is concurrently shown by the results of recent population surveys in the US and in Austria (Martin et al., 2000; Grausgruber, 2000).

Now it was shown that the relative risk for schizophrenic patients to commit a violent act is actually moderately increased in comparison with the general population. Recent epidemiological studies concurrently come to this conclusion (Eronen et al., 1998). However, the attributable risk, i.e. the proportion of violent crimes committed by perpetrators suffering from schizophrenia among the total of violent offences over a certain time period, is minimal. Further, there is no clear evidence for an increase in the amount of violent acts committed by persons with mental illness in recent years (Angermeyer, 2000b). This means that the actual danger posed by those with schizophrenia to the public at large is very small. In contrast to these empirical findings, though, media coverage of the issue produces the picture that the mentally ill in general, and people with schizophrenia in particular, represent a great danger for the population. This impression is the result of selective reporting about mental illness and those suffering from it. Media analyses carried out in Germany, the UK, the US and in Australia showed that media reports in connection with violent offences were particularly frequent - a pattern of reporting that exceeds the actual rate of violent acts committed by people with mental illness by far (Shain \& Phillips, 1991; Barnes \& Earnshaw, 1993; Philo, 1994; Scott, 
1994; Allen \& Nairn, 1997; Hazelton, 1997; HoffmannRichter, 2000; Angermeyer \& Schulze, in press). The fact that media coverage of violent offences committed by the mentally ill can actually have a negative influence on public attitudes could be demonstrated using the example of three violent attacks committed in Germany on public figures by individuals suffering from mental illness (Angermeyer \& Matschinger, 1995). In addition, the stereotype of dangerousness and threat for the social environment is reinforced through the portrayal of mentally ill people in feature films. Here, too, those suffering from mental illnesses are over-represented in the role of the violent criminal (Signorelli, 1989; Hyler et al., 1991; Wilson et al., 1999). Results of a focus group study (Philo, 1996) demonstrate how strongly images from entertainment films can influence ideas of mental illness among viewers.

As the media are a powerful agent in shaping public attitudes, they can also be a central resource in modifying negative stereotypes about mentally ill people. Co-operating with journalists in supporting their research on mental health issues, facilitating contacts with competent persons (including mental health experts, patients and relatives) available for interviews and continuous public relations activities on the part of psychiatric service institutions can help to establish mental health as an independent topic outside the context of crime reporting. At the same time, negative media portrayals should be challenged, using strategies such as stigma watch systems on the internet as operated by NAMI or SANE Australia or letters to the editor. In working with the media, factual information should be combined with personal accounts, communicating everyday experiences of people with mental illness, including periods of successful functioning and life in other social roles but the patient role. This approach is particularly suited for achieving a more realistic portrayal of mental illness in TV programmes or feature films as successfully done by introducing a character who develops schizophrenia in the Australia daily soap "Home and Away". Media awards on mental health reporting have proved to provide an additional incentive for journalists to deal with mental ilIness. Finally, media training programmes can help mental health experts, patients and relatives to develop the necessary skills for working with the media. At the same time, workshops for journalists could be of benefit in providing them with insights in mental health issues.

The stereotype of the violent mentally ill person is not only reinforced by the media, but also by psychiatry itself. While most large-scale mental hospitals were closed in Italy and in the UK, they continue to exist in Ger- many (with one exception). While they underwent extensive renovation and the number of beds was drastically reduced, these institutions continue to project the image of the asylum where one was admitted against one's own will, where compulsory measures are the order of the day, and which are hard to escape. In a 1993 survey, for example, more than half of the respondents were convinced that straightjackets and padded cells are still in regular use at psychiatric hospitals (Angermeyer, 2000a). The impression that these institutions are primarily designed to control aggressive and dangerous individuals is further reinforced through the dire policy to install forensic units on the grounds of the psychiatric hospitals. Changes in the organisation of psychiatric care itself are called for if the association between mental disorders and violence in the eyes of the public is to be counteracted. First and foremost, forensic units should not be part of psychiatric hospitals as their presence coins the public image of everybody receiving treatment at the hospitals concerned. Further, the establishment of psychiatric departments at general hospitals is an important step in ending the spatial isolation of psychiatry.

\section{Separating "Us" from "Them"}

The linking of the label "schizophrenia" to the negative attributes described above provides the basis for the belief that negatively labelled persons are fundamentally different from those who don't share the label, that they belong to a distinct category. Those holding the label are thought to "be" the thing they are labelled (Estroff, 1989). They are not a person who has schizophrenia, but they are "schizophrenics". How, then, can the tendency to reduce a person to a stereotype and the ensuing dissociation from this person be counteracted? Here, personal contact with people suffering from mental illness appears to be the most effective strategy. For the latter allows getting to know the schizophrenic patient as a person with all diverse aspects of his/her personality. $\mathrm{He}$ re, contacts with people living with mental illness should be facilitated from an early age onward. Allowing children and young people to gather personal experience in the contact with mentally ill people can contribute to counteracting stereotypes before they arise or become reinforced (Meise et al., 2000).

In principle, psychiatric reforms aiming at deinstitutionalisation and a better integration of mental health care in the community also pursued the objective of facilitating more contacts between psychiatric patients and the general population, hoping to contribute to a reduc- 
tion of stereotypes by reducing the spatial distance between psychiatric care and the everyday lives of both the patients and their social environment. However, with the current lack of relevant data, the question as to the extent to which community psychiatry has actually achieved an improvement of public attitudes remains unanswered. All the same, the majority of studies investigating the association between personal experience with mentally ill people and attitudes towards them come to a positive conclusion: respondents who had had personal contacts less frequently believed that those with mental illness are dangerous, and they expressed less desire for social distance (Link \& Cullen, 1986; Penn et al., 1994; Whaley, 1997; Trute \& Loewen, 1978; Trute et al., 1989; Hall et al., 1993; Ng et al., 1995; Angermeyer \& Matschinger, 1996). In connection with this, it is important to note that the effect of personal experience appears to be mainly achieved through a change in the emotional reactions towards people with mental illness: pro-social reactions were increased while insecurity and fear were less frequent (Angermeyer \& Matschinger, 1997). An important prerequisite for the success of psychiatric reforms is the establishment of sufficient complementary and out-patient services to replace institutionalised psychiatric care and supplement in-patient treatment offers in the community. Otherwise, as the experience from the US shows, there is a danger that people with mental illness end up being on the streets, and thus become doubly stigmatised: as psychiatric patients and as homeless people.

\section{Discrimination}

As the last step, the stigma process results in the discrimination of the labelled person. With linking a group of people to a set of negative characteristics that sets them apart from others, a justification is constructed for devaluing, rejecting or excluding them. In general, we can distinguish three types of discrimination: direct discrimination, structural discrimination and discrimination through self-stigmatisation (Link \& Phelan, in press). The fact that people with mental illness, and especially those with schizophrenia, continue to be exposed to direct discriminations to this day is welldocumented by the results of the representative public attitude surveys conducted in the last decade (e.g. Brockington et al., 1993; Angermeyer \& Matschinger, 1997; Link et al., 1999). Results of analogue behaviour studies point in the same direction (e.g. Farina \& Fellner, 1973; Farina et al., 1973; Page, 1983). Finally, a substantial amount of direct discrimination also becomes apparent from studies exploring the subjective stigmatisation experiences of people with mental illness (Wahl, 1999; Angermeyer \& Schulze, 2000). Here, interpersonal relationships and the access to employment were found to be the most important areas in which rejection and social exclusion are encountered. However, discrimination does not only occur in the patients' contact with friends and family or with employers. Those confronted with stigma as a result of their mental illness further report concrete incidences of discrimination in their role as a patient. This is equally true for psychiatric and general medical treatment (Angermeyer \& Schulze, 2000). Here, psychiatric institutions should adopt quality assurance strategies to make sure the patients' needs are adequately met. As an example, treatment criteria could be developed jointly by patients and staff. Further, there should be a patient representative monitoring the quality of treatment, acting as a kind of ombudsman who voices patients' concerns and reports incidences of discrimination.

Structural discrimination refers to negative consequences for those with mental illness resulting from imbalances and injustices inherent in social structures, political decisions and legal regulations. The institutional practices can work to the disadvantage of people with mental illness even in the absence of discrimination at the individual level. Mental illnesses, for example, are marginalized in the health care system. As a result of the stigma, less money is devoted to research than for other illnesses, and psychiatric treatment and care are equipped with fewer resources than medical services provided for physical disorders (Link \& Phelan, in press). Further, psychiatric patients face considerable disadvantage in terms of health insurance coverage. In Germany, it is exceedingly difficult to obtain coverage for services specially designed for people with mental illness such as specific forms of psychotherapy and psychiatric care in the community. Budget limitations imposed on office-based psychiatrists often do not allow them to prescribe the (comparatively costly) atypical neuroleptics. Support from pension schemes that are in charge of financing rehabilitation programmes is equally hard to obtain for those with mental illness. Further, travel insurances cover medical care abroad but explicitly exclude payments for any type of mental health care, including medication (Angermeyer \& Schulze, 2000). Structural discrimination can only be reduced through working with decision-makers in politics and health care planning. A public discussion of structural disadvantages is the prerequisite for making the issue 
relevant for decision-makers. Here, lobbying on the part of patient and relatives associations as well as the professional bodies of psychiatry may be a first step in redressing imbalances in the health care system.

The third form of discrimination comes from the patients themselves. In the same way as others, they have learned what it means to be mentally ill in our society in the course of their socialisation. They have an idea of the extent to which those with mental illness will face rejection on the part of their social environment. The more they expect negative reactions; the more insecure they will be in their interaction with others and the more they will be inclined to withdraw from others in order to avoid potential discriminations (Link et al., 1989). This protective behaviour may result in lowered self-esteem (Wright et al., 2000) and demoralisation (Link et al., 1989) as well as in social isolation (Angermeyer et al., 1985; Link et al., 1989), unemployment or loss of income (Link, 1982; 1987) or in a reduced quality of life (Rosenfield, 1997). This tendency to self-stigmatisation can be counteracted by all strategies that serve the empowerment of the patients. Psycho-educational groups in which patients learn to cope with their illness more competently are one example (Brenner et al., 1992; Pekkala \& Merinder, 2000). In addition, cognitive-behavioural therapy programmes which specifically aim at improving stigma coping skills can help to reduce self-stigmatisation (Corrigan, 1998). The most important strategy, however, appear to be self-help groups where patients support each other in more confidently standing up for their interests and in learning how to fight the stigma of their illness.

\section{A note of caution}

The multitude of intervention strategies discussed above should not lead us to overlook the limits to our efforts to reduce the stigma associated with schizophrenia. This already becomes apparent with the stereotype of dangerousness. It should be difficult to relate the complex epidemiological concepts and findings mentioned above to the lay public in such a way that the data will actually persuade them that most of their fears and concerns are without foundation (Crisp et al., 2000; Penn et al., 1999). The attitude towards people with mental illness, then, must not be considered in isolation. To a large extent, it is shaped by individual (as well as collective) value systems and political beliefs that are beyond the influence of our interventions (Angermeyer $\&$ Matschinger, 1997). The working routines of the me- dia and the economic interests shaping the selection of media content set narrow limits to our efforts to achieve a more adequate reporting on mental health issues (Philo, 1997). Further, attempts to reduce structural discrimination are likely to be met with resistance in a time where financial resources for the health care system are increasingly scarce and contested. It is important to bear these limits in mind in order to formulate realistic aims for programmes designed to reduce stigma and discrimination because of schizophrenia.

\section{REFERENCES}

Allen R. \& Nairn R.G. (1997). Media depictions of mental illness: an analysis of the use of dangerousness. Australian and New Zealand Journal of Psychiatry 31, 375-381.

Angermeyer M.C. (2000a). Das Bild von der Psychiatrie in der Bevölkerung. Psychiatrische Praxis 27, 327-329.

Angermeyer M.C. (2000b). Schizophrenia and violence. Acta Psychiatrica Scandinavica 102 (Suppl. 407), 63-67.

Angermeyer M.C. \& Matschinger H. (1995). Violent attacks on public figures by persons suffering from psychiatric disorders. European Archives of Psychiatry and Clinical Neuroscience 245, 159164.

Angermeyer M.C. \& Matschinger H. (1996). The effect of personal experience with mental illness on the attitude towards individuals suffering from mental disorders. Social Psychiatry and Psychiatric Epidemiology 31, 321-326.

Angermeyer M.C. \& Matschinger H. (1997). Social distance towards the mentally ill: results of representative surveys in the Federal Republic of Germany. Psychological Medicine 27, 131-141.

Angermeyer M.C. \& Schulze B. (2000). Lo stigma dal punto di vista di chi soffre di schizophrenia e delle loro familie. I risultati di un gruppo di studio in Germania. In Lotta allo Stigma (ed. F. Asioli e M. Bassi), pp. 29-47. Editrice Compositori: Bologna.

Angermeyer M.C. \& Schulze B. (in press). Reinforcing stereotypes: The focus on forensic cases in news reporting and its influence on public attitudes towards the mentally ill. International Journal of Law and Psychiatry.

Angermeyer M.C., Lammers R. \& Hoffmann J. (1985). Sozialer Rückzug: Reaktion auf das Stigma psychischer Krankheit? Medizin Mensch Gesellschaft 10, 132-136.

Barnes R.C. \& Earnshaw S. (1993). Mental illness in British newspapers. Psychiatric Bulletin 17, 673-674.

Brenner H.D., Hodel B., Roder V. \& Corrigan P. (1992). Treatment of cognitive dysfunctions and behavioural deficits in schizophrenia: integrated psychological therapy. Schizophrenia Bulletin 18(1), 21-26.

Brockington I.F., Hall P., Levings J. \& Murphy C. (1993). The community's tolerance of the mentally ill. British Journal of Psychiatry 162, 93-99.

Corrigan P. W. (1998) The impact of stigma on severe mental illness. Cognitive and Behavioural Practice 5, 201-222.

Crisp A.H., Gelder M.G., Rix S., Meltzer H.I. \& Rowlands O.J. (2000). Stigmatisation of people with mental illness. British Journal of Psy. chiatry 177, 4-7.

Crocker J., Major B. \& Steele C. (1998). Social stigma. In The Hand- 
book of Social Psychology, vol. 2 (ed. D.T. Gilbert, S.T. Fiske and G. Lindzey), pp. 504-553. McGraw-Hill: Boston, MA.

Eronen M., Angermeyer M.C. \& Schulze B. (1998). The psychiatric epidemiology of violent behaviour. Social Psychiatry and Psychiatric Epidemiology 33, S13-S23.

Estroff S.E. (1989). Self, identity and subjective experiences of schizophrenia: in search of the subject. Schizophrenia Bulletin 15, 189196.

Farina A. \& Felner R.D. (1973). Employment interviewer reactions to former mental patients. Journal of Abnormal Psychology 82, 268272.

Farina A., Felner R.D. \& Bourdreau L A. (1973). Reactions of workers to male and female mental patient job applicants. Journal of Consulting and Clinical Psychology 41, 363-327.

Farina A., Fisher J.D. \& Getter H. (1978). Some consequences of changing people's views regarding the nature of mental illness. Journal of Abnormal Psychology 2, 272-279.

Fisher J.D. \& Farina A. (1979). Consequences of beliefs about the nature of mental disorders. Journal of Abnormal Psychology 3, 320327.

Goffman E. (1963). Stigma: Notes on the Management of Spoiled Identity. Prentice Hall: Englewood Cliffs NJ.

Grausgruber A. (2000). Attitudes of the general population concerning schizophrenia. Paper presented at 10th Congress of the Association of European Psychiatrists, Prague.

Hall P., Brockington I.F., Levings J. \& Murphy C. (1993). A comparison of responses to the mentally ill in two communities. British Journal of Psychiatry 162, 99-108.

Hayward P. \& Bright, J. A. (1997). Stigma and mental illness: a review and critique. Journal of Mental Health 6, 345-354.

Hazelton M. (1997). Reporting mental health: a discourse analysis of mental health-related news in two Australian newspapers. Australian and New Zealand Journal of Mental Health Nursing 6, 73-89.

Hoffmann-Richter U. (2000). Psychiatrie in der Zeitung. Urteile und Vorurteile. Das Narrenschiff im Psychiatrie-Verlag: Bonn.

Hyler S.E., Gabbard G.O. \& Schneider 1. (1991). Homicidal maniacs and narcissistic parasites: Stigmatization of mentally ill persons in the movies. Hospital and Community Psychiatry 10, 1044-1048.

Link B.G. (1982). Mental patient status, work, and income: an examination of the effects of a psychiatric label. American Sociological Review 47, 202-215.

Link B.G. (1987). Understanding labeling effects in the area of mental disorders: An assessment of the effects of expectations of rejection. American Sociological Review 52, 96-112.

Link B.G. \& Cullen F.T. (1986). Contact with the mentally ill and perceptions of how dangerous they are. Journal of Health and Social Behaviour 27, 289-303.

Link B G. \& Phelan J.C. (in press). On The Nature and Consequences of Stigma. Annual Review of Sociology.

Link B.G., Cullen F.T., Struening E.L., Shrout P. \& Dohrenwend B.P. (1989). A modified labeling theory approach in the area of mental disorders: An empirical assessment. American Sociological Review $54,100-123$.

Link B.G., Struening E.L., Rahav M., Phelan J.C. \& Nuttbrock L.(1997). On stigma and its consequences: Evidence from a longitudinal study of men with dual diagnosis of mental illness and substance abuse. Journal of Health and Social Behavior 38, 177-190.

Link B.G., Phelan, J.C., Bresnahan M., Stueve A. \& Pescosolido B. A. (1999). Public conceptions of mental illness: Labels, causes, dangerousness, and social distance. American Journal of Public Health 9, 1328-1333.
Martin J.K., Pescosolido B.A. \& Tuch S. A. (2000). Of fear and loathing: the role of 'disturbing behavior', labels, and causal attributions in shaping public attitudes toward people with mental illness. Journal of Health and Social Behavior 41, 208-223.

Mechanic D., McAlpine D., Rosenfield S. \& Davis D. (1994). Effects of illness attribution and depression on the quality of life among persons with serious mental illness. Social Science and Medicine $2,155-164$.

Meise U., Sulzenbacher H., Kemmler G., Schmid R., Rössler W. \& Günther, V. (2000). "... nicht gefährlich, aber doch furchterregend". Ein Programm gegen Stigmatisierung von Schizophrenie in Schulen. Psychiatrische Praxis 27, 340-346.

Ng S.L., Martin J.L. \& Romans S. E. (1995). A community's attitude towards the mentally ill. New Zealand Medical Journal 108, 505 508.

Page S. (1983). Psychiatric stigma: two studies of behaviour when the chips are down. Canadian Journal of Community Mental Health 1, 13-19.

Pekkala E. \& Merinder L. (2000). Psychoeducation for schizophrenia (Cochrane Review). Cochrane Database Systems Review 4: CD002831.

Penn D.L., Guynan K., Daily T., Spaulding W.D., Garbin C.P. \& Sullivan M. (1994). Dispelling the stigma of schizophrenia: what sort of information is best? Schizophrenia Bulletin 20, 567-578.

Penn D.L., Kommana S., Mansfield M. \& Link B.G. (1999). Dispelling the stigma of schizophrenia: II. The impact of information on dangerousness. Schizophrenia Bulletin 25, 437-446.

Pescosolido B.A., Monahan J., Link B.G., Stueve A. \& Kikuzawa S. (1999). The public's view of the competence, dangerousness, and need for legal coercion of persons with mental health problems. American Journal of Public Health 89, 1339-1345.

Philo G. (1994). The impact of the mass media on public images of mental illness: media content and audience belief. Health Education Journal 53, 271-281.

Philo G. (ed.) (1996). Media and Mental Distress. Longman: London. Philo G. (1997). Changing media representations of mental health. Psychiatric Bulletin 21, 171-172.

Rosenfield S. (1997). Labeling mental illness: the effects of received services and perceived stigma on life satisfaction. American Sociological Review 62, 660-672.

Rothaus P., Hanson P.G., Cleveland S.E. \& Johnson D.L. (1963). Describing psychiatric hospitalization: a dilemma. American Psychologist $18,85-89$.

Sartorius, N. (1998). Stigma: what psychiatrists can do about it? Lancet, Sep 26, 325 (9133), 1058-1059.

Scott J. (1994). What the papers say. Psychiatric Bulletin 18, 489-491. Shain R.E. \& Phillips J. (1991). The stigma of mental illness: labelling and stereotyping in the news. In Risky Business: Communicating Issues of Science, Risk and Public Policy (ed. L. Wilkins and P. Patterson), pp. 61-74. Greenwood press: Westport, CT.

Signorelli N. (1989). The stigma of mental illness on television. Journal of Broadcasting and Electronic Media 33, 325-331.

Socall D.W. \& Holtgraves T. (1992). Attitudes toward the mentally ill: The effect of label and beliefs. Sociological Quarterly 3, 435445.

Trute B. \& Loewen A. (1978). Public attitude toward the mentally ill as a function of prior personal experience. Social Psychiatry 13, 79-84.

Trute B., Tefft B. \& Segall A. (1989). Social rejection of the mentally ill: a replication study of public attitude. Social Psychiatry and Psychiatric Epidemiology 24, 69-76. 
Wahl O.F. (1999). Mental health consumers' experience of stigma. Schizophrenia Bulletin 3, 467-478.

Wahl O.F. \& Lefkowits, J. Y. (1989). Impact of a television film on attitudes toward mental illness. American Journal of Community Psychology 17, 521-528.

Whaley A.L. (1997). Ethnic and racial differences in perception of dangerousness of persons with mental illness. Psychiatric Services 48 , 1328-1997.
Wilson C., Nairn R., Coverdale J. \& Panapa A. (1999). Mental illness depictions in prime-time drama: identifying the discursive resources. Australian and New Zealand Journal of Psychiatry 33, 232239.

Wright E.R., Gonfreins W.P. \& Owens T.J. (2000). Deinstitutionalization, social rejection, and the self-esteem of former mental patients. Journal of Health and Social Behavior 41, 68-90. 